\title{
Sex Workers in the Context of Sexually Transmitted Infections: An Evaluation of Rapid Test Markers and Risk Factors
}

\author{
Pereira, Daiane Costa ${ }^{1}$, Rodrigues Geisiane Sandra ${ }^{2}$, Francisco, Higor Adrian Dos Santos ${ }^{3}$, \\ Romanholo Rafael Ayres ${ }^{4}$, Romanholo Helizandra Simoneti Bianchini ${ }^{5}$ \\ ${ }^{1}$ Bachelor of Nursing from Faculdade de Ciências Biomédicas de Cacoal - FACIMED (2018). Resident in Obstetric Nursing in the \\ Municipality of Vilhena, Ministério da Saúde \\ 2,3 Bachelor of Nursing from Faculdade de Ciências Biomédicas de Cacoal - FACIMED (2018). E-mail: geise.sandra@ hotmail.com \\ ${ }^{4}$ Ph.D. in Regional and Environmental Development - UNIR (2018). Professor at Instituto Federal de Rondônia - IFRO \\ ${ }^{5}$ Masters in Health Sciences from Instituto de Assistência Médica ao Servidor Público Estadual - IAMSPE (2017). Professor of Nursing \\ Course and Medicine Course at Faculdade de Ciências Biomédicas de Cacoal - FACIMED
}

\begin{abstract}
This is a field study, of descriptive and quantitative approach, with transversal characteristics. The objective was to identify the rapid test markers for Anti-HCV, HBsAG, Syphilis and HIV and risk factors for Sexually Transmitted Infections (STIs) of the prostitutes of the city of Cacoal / RO. The sample consisted of 16 sex workers who work in the brothels in the municipality of Cacoal / $R O$. The research data were collected through the application of a questionnaire composed of 17 questions, along with informed consent form (TCLE), and then the professionals were referred for rapid testing with the trained nurse practitioner. It was observed that 16 (100\%) of the interviewees were female, with a mean age of 27.4 years, 8 (50\%) of the sex workers completed high school, 2 (12.5\%) have incomplete higher education and 1 (6.2\%) complete higher education. When questioned about the number of partners, 6 (37.5\%) attended at least 2 clients per day. Of the $6(37.5 \%)$ sex workers who had a vaccination card, had a vaccine scheme for hepatitis $B$ virus, 15 (93.8\%) had negative results for the STIs investigated, and 1 (6.2\%) presented a syphilis reagent result, which was sent to the UBS for investigation, diagnosis and treatment. The main risk factors were non-use of condoms in some sexual relationships, lack of vaccination cards and lack of knowledge about STI transmission routes.
\end{abstract}

Keywords: Sex workers. Sexually Transmitted Infections, Risk factors

\section{Introduction}

The term prostitution derives from the Latin prosto, which means "to be in sight, waiting for those who want to arrive or to be exposed to the public eye [...] is the usual and promiscuous paid sexual practice" (FRANÇA 2012, p.145). In 2003, labor legislation included prostitution in the Brazilian Classification of Occupations, which considers "a sex worker, to be every person over 18 years old and absolutely capable who voluntarily provides sexual services for remuneration" (BRASIL, 2007).

Due to their sexual conduct, sex workers are more susceptible to prejudice and social exclusion, since their figure is always associated with the transmission of STIs, the use of drugs and violence (LEITÃO et al., 2012).

The risks sex professionals are subject to include mainly insecure work environment, susceptibility to violence (sexual, psychological, verbal and physical), alcoholism, use of illicit drugs, as well as STIs contracted from unprotected sexual relationships. Despite knowledge of the need for condom use and its benefits, many sex workers neglect using them in relationships with permanent partners (LEAL et al., 2017).

Considered a public health problem that affects the entire world, STIs are caused by viruses, bacteria or other microorganisms. The main means of transmission is through unprotected sexual contact (oral, vaginal and anal) with an infected person. The most vulnerable population for STIs are homosexuals, transsexuals and sex workers. The screening of these diseases in high-risk professionals enables appropriate treatment, a better quality of life and interruption of the transmission chain for these infections (BRASIL, 2018a).

Due to multiple partners, sex workers are more likely to contract a sexually transmitted infection (STI), as they work with clients with unknown sexual histories. Therefore, STIs have become an imminent risk for these professionals, who use sexual intercourse as the raw material of their service (MOURA et al., 2010). Thus, whenever possible, laboratory tests or RTs should be used to assist in defining the diagnosis. In addition, whenever available at the health service, tests should be carried out to screen for gonorrhea, chlamydia, syphilis, HIV and hepatitis B and C (BRASIL, 2018a).

Therefore, this study is justified by the need to identify the profile of the RT markers and the risk factors for STIs, most commonly faced by sex professionals during the exercise of their profession. The study will offer information that allows health services to create a set of individual and collective strategies aimed at this population, thereby reducing the risks and harm derived from their profession, allowing sex workers to choose the prevention method that best suits their life conditions for prevention of STIs. Furthermore, early diagnosis of STIs, enables early treatment for a better quality 


\section{International Journal of Science and Research (IJSR) \\ ISSN: 2319-7064}

ResearchGate Impact Factor (2018): 0.28 | SJIF (2019): 7.583

of life, reduces complications and interrupts the transmission chain of some infections.

The research hypothesis is that there are a high number of positives for Anti-HCV, HBsAG, syphilis and HIV among sex workers in the municipality of Cacoal / RO, Brazil.

Given the above, the general objective of the research was to identify rapid testing markers for Anti-HCV, HBsAG, syphilis and HIV and the risk factors for STIs of sex workers from the municipality of Cacoal / RO. The specific objectives were to characterize sex workers in relation to gender, mean age and level of education; investigate the number of sexual partners of each professional daily and time of profession; evaluate their vaccination card regarding the vaccination schedule against Hepatitis B virus; inquire about the use of condoms during sexual intercourse (vaginal, anal and oral), and identify if they have already undergone treatment for STIs.

\section{Material and Methods}

This is a descriptive field study with a quantitative approach and a transversal characteristic carried out in brothels in the municipality of Cacoal / RO. Five brothels were identified through a survey and information from nurses in the Basic Health Units (BHU), however only four brothels were included in the study, because the head of one of the brothels refused to participate. Of the 04 brothels visited, 21 sex workers were identified, and the study sample consisted of 16 of these, since 5 sex workers were approached and later excluded from the sample for declining to sign the free and informed consent form.

The project was developed in partnership with the Municipal Health Secretariat of Cacoal, through the Coordination of Sexually Transmitted Infections and Coordination of Health Surveillance, which provided the RTs, condoms, lubricating gels, thermal box and a professional nurse trained for the testing.

Initially, visits were made to the 05 brothels, where the researchers identified themselves with a badge showing the name, course and educational institution they represent. Then, the project was presented to the person in charge of the establishment and authorization was requested to conduct the research; four of these brothels granted authorization.

Secondly, a meeting was held, during which the date and time as established by sex professionals for the data collection were scheduled; to be held in the afternoon in the brothel outside working hours, in order not to interfere during client service hours.

The third step, as scheduled previously, the researchers, accompanied by the nursing professional from the Municipal Health Department of Cacoal, performed the HIV, Syphilis, Anti-HCV and HBsAG RTs and applied the questionnaire. All the participants' questions were answered beforehand and the informed consent form was signed in duplicate with one copy returned to the researchers and the other kept by the research participant. An educational lecture of approximately 15 minutes was carried out by the researchers, in which topics related to STIs were addressed (concept, signs and symptoms, prevention and treatment), as well as pre-test counseling as recommended by the Ministry of Health (MS). On that occasion, an explanatory folder about the RTs was delivered and lubricating gels and male and female condoms were distributed. After these procedures, a questionnaire prepared by Prudêncio et al., (2004) and adapted by the researchers was applied, containing 17 questions, 11 of which were objective and 06 descriptive, which were answered by the interviewees. Shortly after completion of the questionnaire, the sex workers were submitted to the RTs.

The RTs were performed individually, in the presence of only the professional nurse who performed the RTs and the sex worker at the chosen location within the brothel, as well as post-test counseling and delivery of the examination result report. Thus, the result remained confidential and did not cause any discomfort to the workers. At all times, absolute confidentiality of the information provided was guaranteed, which was exclusively for research purposes, and at no time during this research would participants be exposed, or have their name or address disclosed.

Having completed all the procedures for applying the questionnaire and RTs, the participant who presented a rapid test reagent for Syphilis was referred by the nursing professional to the UBS in her locality for complementary exams, diagnosis, treatment and follow-up. The case reagent for syphilis was notified in a specific form, for acquired syphilis, as standardized by the MS. It is underscored that the care for this patient with a reagent rapid test complied with the sequence of care already recommended by the Municipal Health Department of Cacoal.

After data collection, the data were tabulated, analyzed and presented descriptively and in tables using Microsoft Word 2016 and Microsoft Excel 2016. For statistical analysis, the Bioestatic 2.0 program was used for relative frequency, absolute frequency, mean, standard deviation, and finally, to compare the RT results the $\mathrm{Z}$ test was used with a value of $\mathrm{p}$ $<0.5$.

The research was carried out after approval by the Ethics and Research Committee of the Cacoal Educational Institution - FACIMED, as cited in Resolution No. 466, of December 12, 2012 and Resolution No. 510, of April 7, 2016 of the National Health Council, according to CAAE approval protocol: 88640418.8.0000.5298.

\section{Results and Discussion}

The study sample consisted of 16 sex workers, who work in brothels in the municipality of Cacoal / RO. It should be noted that all were female $(100 \%)$, with a mean age of 27.4 years, ( \pm 4.9 years), the youngest being 19 years old and the oldest 36 .

Regarding schooling, it is observed that $5(31.3 \%)$ of sex workers have completed high school, followed by $4(25 \%)$ with incomplete elementary school, 3 (18.8\%) incomplete high school, 2 (12.5\%) incomplete higher education, 1 


\section{International Journal of Science and Research (IJSR) \\ ISSN: 2319-7064}

ResearchGate Impact Factor (2018): 0.28 | SJIF (2019): 7.583

(6.2\%) complete higher education and $1(6.2 \%)$ complete elementary education.

Regarding the RTs performed on sex workers for HIV, Anti$\mathrm{HCV}$ and HBsAg, 16 (100\%) of the respondents presented a non-reagent result, and for syphilis only $1(6.2 \%)$ of the participants had a reagent rapid test, albeit not presenting a significant result with a value of $\mathrm{p}=0.835$, as shown in Table 1. That is, taking into account that $\mathrm{p}$ value is equal to significance, and that a result of $\mathrm{p}$ greater than 0.5 is not considered significant. The $\mathrm{Z}$ test result, with $\mathrm{p}=0.835$, shows that the probability of this reagent rapid test in the sample representing this population is approximately $92 \%$, which indicates that this result may have been due to chance, since to be considered a significant result there would have to be a minimum probability of $95 \%$.

After performing RTs, the participant who presented a reagent rapid test for Syphilis was referred by the nursing professional to the UBS of the locality for complementary exams, diagnosis, treatment and follow-up.

Table 1: Distribution of Rapid Test results for HIV, Anti$\mathrm{HCV}, \mathrm{HBsAG}$, and Syphilis performed on sex workers in the municipality of Cacoal / Rondônia, Brazil 2018.

\begin{tabular}{|c|c|c|c|c|}
\hline RESULT & HIV & HBsAG & Anti-HCV & SYPHILIS \\
\hline Reagent & $0(0 \%)$ & $0(0 \%)$ & $0(0 \%)$ & $1(6.2 \%)$ \\
\hline $\begin{array}{c}\text { Non-reagent } \\
\text { Z }\end{array}$ & $16(100 \%)$ & $16(100 \%)$ & $16(100 \%)$ & $15(93.8 \%)$ \\
$1.7308 \%$ \\
\hline
\end{tabular}

Legend: $\mathrm{Z}=\mathrm{Z}$-test for comparison between groups $/$ * $\mathrm{p}=0.835$.

Source: The authors, 2018.

Table 2 shows the distribution of variables related to risk factors for STIs, it is noted that the majority of sex workers $9(56.3 \%)$ have worked in this profession for more than 1 year and less than 5 years, while the shortest time in the profession was 3 weeks, and the longest was 15 years. When asked if they had already undergone treatment for any STI, $16(100 \%)$ sex workers reported that they had never undergone treatment. Regarding the use of condoms during sexual intercourse, it is observed that $16(100 \%)$ use a male condom during vaginal intercourse, however not all use condoms when it comes to oral and / or anal sex. Regarding the number of clients served per day, the majority of sex workers $6(37.5 \%)$ serve on average 2 per day, followed by $5(31.3 \%)$ sex workers who serve 4 or more per day. Regarding the HBV vaccination scheme, most sex workers $10(62.5 \%)$ did not have a vaccination card.

Table 2: Distribution of variables related to risk factors for STIs among sex workers in the municipality of Cacoal / Rondônia, Brazil, 2018

\begin{tabular}{|l|c|c|}
\hline Variables & $\mathrm{n}$ & $\%$ \\
\hline Time in Profession & & \\
\hline$<1$ year & 2 & 12.5 \\
\hline$>1$ year and < 5 years & 9 & 56.3 \\
\hline$>5$ years and <10 years & 2 & 12.5 \\
\hline$>10$ years & 3 & 18.7 \\
\hline Have you been treated for STIs? & & \\
\hline Yes & 0 & 0 \\
\hline No & 16 & 100 \\
\hline Use of preservative during relations: & & \\
\hline
\end{tabular}

\begin{tabular}{|l|c|c|} 
Oral & & \\
\hline Yes & 14 & 87.5 \\
\hline No & 2 & 12.5 \\
\hline Anal & & \\
\hline Yes & 15 & 93.8 \\
\hline No & 1 & 6.2 \\
\hline Vaginal & & \\
\hline Yes & 16 & 100 \\
\hline No & 0 & 0 \\
\hline Number of partners per day & & \\
\hline 1 & 2 & 12.5 \\
\hline 2 & 6 & 37.5 \\
\hline 3 & 3 & 18.7 \\
\hline 4 or more & 5 & 31.3 \\
\hline Vaccination scheme for HBV: & & \\
\hline Complete & 6 & 37.5 \\
\hline Incomplete & 0 & 0 \\
\hline Does not have a vaccination card & 10 & 62.5 \\
\hline
\end{tabular}

Legend: $<=$ less; > = more.

Source: The authors, 2018.

The present study showed that the sex workers surveyed in the brothels in the municipality of Cacoal / RO are female, with a mean age of 27.4 years and a minimum age of 19 years and a maximum age of 36 years, an age still considered active for the profession. This study presented data similar to other research carried out with groups of professionals in various regions of the country. Raiol et al., (2014) in a study on 153 sex workers, carried out in five municipalities and 18 riverside communities in the Marajó Archipelago, found a mean age of 23.5 years ( \pm 5.5 years), all of which were female. Likewise, Penha et al., (2010) in her study, with 73 sex workers in the municipality of Picos / PI, found a mean age of 25 years and a $100 \%$ prevalence of female professionals.

Regarding education, it can be seen that $8(50 \%)$ sex workers have a high level of education, since they have completed high school and some are attending or have completed higher education. It is observed that over the years, the level of education of sex workers has increased compared to the articles published by Prudêncio et al., (2004), Moura et al., (2010) and Leitão et al., ( 2012), in which most professionals were unable to attend high school and a large proportion was illiterate.

Prudêncio et al. (2004) in his study, with 24 sex workers in the city of Castelo / PI, found a low level of education, with $3(12.5 \%)$ being illiterate, $19(79.2 \%)$ had incomplete elementary education and $2(8.3 \%)$ incomplete high school. Moura et al., (2010) in their study, conducted with 25 sex workers in Fortaleza / CE, found a higher rate of participants who are completing elementary school, 15 (60\%).In the latter study, the low level of education was seen as one of the factors for these professionals to enter and remain in this profession, since they would be unable to find other work in the job market.

However, the low level of education factor can no longer be taken into account for the present study, since sex workers present a higher level of education. In this study, it is underscored that $8(50 \%)$ of the professionals have completed high school, of which $1(6.2 \%)$ is in higher 


\section{International Journal of Science and Research (IJSR) \\ ISSN: 2319-7064}

ResearchGate Impact Factor (2018): 0.28 | SJIF (2019): 7.583

education and another, 1 (6.2\%) has finished higher education and no cases of illiteracy were reported.

The level of education proved to be very important for the understanding of women sex workers in relation to care for prevention of STIs from the sex trade, and it also facilitates an understanding of preventive actions to be carried out in their workplace.

Regarding the RTs performed on sex workers, it was observed that there was only 1 sex worker who presented a reagent rapid test for syphilis out of the 16 submitted to the tests, and when the statistical test was applied, it was found that this case of positivity alone was not significant compared to the study sample. Sex workers have a greater risk of contracting STIs due to the large number of partners, their sexual history, unknown clients and since the raw material for their work is sexual relations which is the principal means for transmission of STIs (MOURA et al., 2010). Therefore, the present study does not corroborate the findings reported by Moura, this can be justified in part by the higher level of education, greater knowledge regarding the risks, understanding the importance of condom use and by avoiding situations that they consider would put themselves at risk.

The fact of finding a rapid reagent test for syphilis is in accordance with the Ministry of Health stating (2017, p.5) that in the last 5 years there has been a constant increase in the number of syphilis cases in Brazil, which is due , in part, to the increase in testing coverage following the greater use of RTs. It is believed that if the rapid test had not been performed in the brothel, the participant with a reagent test probably would not have sought the Basic Health Unit to perform it, since she did not present any signs and symptoms of the disease at the time of the research.

Regarding the participant with the reagent result for syphilis, she could indicate a serological scar or reinfection; however, during the questionnaire she replied that she had never undergone any treatment for any of the STIs surveyed. Thus it is suggested that she has the disease in the latency period, given that she did not report the presence of any of the symptoms of the disease at the time.

According to the Ministry of Health (2017), "in [...] cases of positive RTs (reagent), a blood sample should be collected and sent for a laboratory test (nontreponemal) to confirm the diagnosis". Thus, the attendance for the participant followed the recommendations by the Ministry of Health and those established by the Municipal Health Secretariat of Cacoal.

Regarding the risk factors for STIs, it can be observed that most of the sex workers had been in the profession for more than a year, with some working for over 10 years. According to Leal et al. (2017), the longer in the profession, the greater the exposure to risk of infection, however the lack of effective contagion, causes professionals to underrate the potential for virus infection, which in turn weakens preventive actions.

Also identified as a risk factor for STIs in this study was the number of partners, since most sex workers reported 2 or more partners per day. Aquino et al. (2008), reported that multiple partners with unknown sexual histories already makes these professionals vulnerable to STIs.

Another risk factor found is the non-adherence to condom use in oral and / or anal intercourse reported by $3(18.7 \%)$ of sex workers, a small number when compared to other studies such as Moura et al. (2010), who reported that out of 25 participants, 11 said they did not use condoms in some situations during the exercise of their profession. In this study, all interviewees reported using condoms during vaginal intercourse and refusing to accept a higher payment for not using condoms. It is evident that there is a greater concern for the transmission of STIs through the vaginal route and neglect regarding the other routes of transmission. According to the Ministry of Health, the use of condoms is the best known, accessible and effective method to prevent STIs, in addition to avoiding unplanned pregnancy (BRASIL, 2018b).

Another very important factor that is evident is that some of the interviewees do not have a vaccination card. This type of situation makes it difficult for health professionals and professionals to assess their immunization against hepatitis $\mathrm{B}$ virus (HBV), considering that it is a free vaccine, offered by the Unified Health System (SUS) and is effective for prevention of this disease. For those who have lost their vaccination card, the orientation is to return to the health clinic where they received the vaccines in order to retrieve the vaccination history and obtain a duplicate. The absence of the vaccination card is not an impediment to vaccinating (BRASIL, 2018c).

\section{Final Considerations}

It is concluded that the main risk factors found for STIs was the large number of partners, time in the profession, nonadherence to condom use in sexual intercourse by anal and oral route and the lack of evidence for hepatitis B vaccine. In the study population, only one positive case for syphilis was identified, and the statistical test applied indicated that this case of positivity alone was not significant compared to the study sample, and as such it cannot be stated that the study population presents an increased risk factor for STIs, which does not confirm the hypothesis raised in the study that there is a high number of positives for Anti-HCV, HBsAG, syphilis and HIV among sex workers in the city of Cacoal/ RO.

It is suggested that the UBS in the coverage areas develop educational actions on STIs, prevention of breast and cervical cancer, distribution of condoms and lubricating gels, and even more campaigns are recommended with rapid tests carried out in brothels for early detection of diseases such as HIV, Syphilis, HCV and HBV, thereby breaking the chain of transmission and achieving early treatment of infections in cases of positivity.

\section{References}

[1] AQUINO, P. S. et al. Perfil sociodemográfico e comportamento sexual de prostitutas de Fortaleza-CE. Texto Contexto Enfermagem, Florianópolis, v. 17, n. 3, p. 427-434, 2008.

\section{Volume 9 Issue 5, May 2020


[2] BEIGUEKMAN, B. Curso prático de bioestatística $-4^{\mathrm{a}}$ ed. rev. Sociedade Brasileira de Genética, Ribeirão Preto, 1996.

[3] BRASIL, Ministério da Saúde. Secretaria de Vigilância em Saúde. Boletim epidemiológico. Brasília: Ministério da Saúde, 2017.

[4] BRASIL, Ministério do Trabalho. Classificação Brasileira de Ocupações-CBO. Distrito Federal, 2007.

[5] BRASIL, Ministério da Saúde, Departamento de ist, aids e hepatites virais. Portal sobre aids, doenças sexualmente transmissíveis e hepatites virais. 2018a.

[6] BRASIL, Ministério da Saúde. Prevenção combinada. 2018b.

[7] BRASIL, Ministério da Saúde, Programa nacional de imunização, 2018c. Disponível em: http://portalms.saude.gov.br/acoes-eprogramas/vacinacao/calendario-vacinacao.

[8] BRASIL, Ministério da Saúde. Coordenação de doenças sexualmente transmissíveis e Aids. Sífilis: Estratégias para Diagnóstico no Brasil. Brasília: Ministério da Saúde. 2010. 100 p.

[9] FRANÇA, G. V. Prostituição: um enfoque político social. Femina, Rio de Janeiro, v. 22, n. 2, p. 145-148, 2012.

[10]LEAL, Carla Bianca de Matos; SOUZA, Dieslley Amorim de; RIOS, Marcela Andrade. Aspectos de vida e saúde das profissionais do sexo. Rev. Enferm. Ufpe OnLine, Recife, v. 11, n. 11, p.4483-4491, nov. 2017.

[11]LEITÃO, Elouyse Fernandes et al. A prática cotidiana de saúde das profissionais do sexo. 2012. ed. 1 Fortaleza: Rev. Bras. Promoç. Saúde, 2012. 295- 304 p.

[12] MOURA, Ana Débora Assis et al. O comportamento de prostitutas em tempos de aids e outras doenças sexualmente transmissíveis: como estão se prevenindo? Florianópolis. ed. 1 Exto Contexto Enferm, 2010. 545$53 \mathrm{p}$.

[13] PENHA, Jardeliny Corrêa et al. Fatores de risco para doenças sexualmente transmissíveis em profissionais do sexo do interior piauiense. Piauí. Rev. Gaúcha de Enfermagem, 2010.

[14] PRUDÊNCIO, Fabrícia Araújo et al. Artigo científico. Profissionais do sexo no contexto das doenças sexualmente Transmissíveis: uma contribuição para análises Epidemiológicas. 2004.

[15] RAIOL, Naíris C. et al. Vulnerabilidade às infecções sexualmente transmissíveis das mulheres que comercializam sexo em municípios e comunidades no arquipélago do Marajó, Pará. Pará. Rev. Convibra, 2014. 